\title{
Introduction to special section: Synoptic and mesoscale weather systems in the polar regions
}

\author{
David H. Bromwich ${ }^{1}$ \\ Polar Meteorology Group, Byrd Polar Research Center, Ohio State University, Columbus
}

This special section consists primarily of papers contributed to Symposium M-9 on Synoptic and Mesoscale Weather Systems in the Polar Regions at the XXI General Assembly of the International Union of Geodesy and Geophysics, which was held in Boulder, Colorado, during July 1995 . The symposium was convened by John Turner of the British Antarctic Survey and Erik Rasmussen of the University of Copenhagen.

High-latitude meteorology is in a period of rapid transition away from being a generally neglected area of atmospheric science. With the general understanding that the atmospheric and oceanic circulation is to first order driven by the thermal contrast between the equatorial heat source and the polar heat sinks, it no longer seems appropriate to deemphasize the role of the polar regions in climate variability and change. However, the natures of the Arctic and Antarctic are profoundly different. The ice-covered and land-locked Arctic Ocean contrasts with the elevated and extensive Antarctic ice sheets that are surrounded by the Southern Ocean. The very different geographic characteristics limit the similarities between these two regions.

Polar atmospheric studies have been hampered by the remoteness of these areas, their demanding climate, and the shortage of observations. The increasingly accurate and expanding range of variables derived from satellite observations combined with the development and widespread deployment of automatic weather stations and drifting buoys is decreasing the data void. Numerical modeling is becoming an important analysis tool. In particular, data assimilation is emerging as an important approach to integrate diverse and sparse data sources into a coherent description of the threedimensional, time-dependent atmospheric circulation. The trend is away from broad-scale studies to more detailed investigations such as the Surface Heat Budget of the Arctic Ocean (SHEBA) [Moritz and Perovich, 1996] and the First Regional Observing Study of the Troposphere (FROST) [Turner et al., 1996]. The first project addresses the energy exchanges among the atmosphere, sea ice, and upper Arctic Ocean. FROST is directed toward examining and improving the performance of weather forecast models poleward of $50^{\circ} \mathrm{S}$ latitude.

The symposium was designed to advance the understanding of the role of the polar atmospheres in the general circulation by better resolving synoptic and mesoscale circulation systems in high latitudes. Emphasis was placed on describing their structure, dynamics, and climatology. In

\footnotetext{
IAlso at Atmospheric Sciences Program, Ohio State University, Columbus.

Copyright 1997 by the American Geophysical Union.

Paper number 97JD01307.

0148-0227/97/97JD-01307\$09.00
}

particular, cyclones play an essential role in these latitudes by transporting heat and moisture poleward. They are the primary cause of precipitation and are integral to the behavior of the planetary boundary layer. The correct representation of synoptic and mesoscale cyclones is an essential but challenging requirement for operational forecast models and global climate models (GCMs). The symposium had a theme of how different components of the climate system are related to cyclonic activity.

The strong air-ocean-ice interactions in the polar regions dictate a wide range of research strategies which could appear in many different journals. The geographic focus adopted here illuminates the great strides being made in polar meteorology during this transition period; this stage of subject development means that the scope of this special section is broader than is typical. The section was extended by soliciting additional manuscripts that were closely related to those presented at the symposium. This guest editor supervised the review of all papers except those he coauthored, which were primarily handled by Guest Editor Hiroshi Kanzawa.

Following this introduction are 22 articles, of which the first 11 have been approximately ordered according to decreasing spatial scale. This is followed by seven papers on mesoscale cyclones and by four on precipitation. First, Krinner et al. [this issue] describe credible GCM simulations of Antarctic climate with a variable grid mesh that is about $100 \mathrm{~km}$ over Antarctica and degrades northward. An effective alternative approach with some caveats is presented by Hines et al. [this issue] where a $100 \mathrm{~km}$ resolution mesoscale model is nested within a GCM. A spatial resolution of $100 \mathrm{~km}$ resolves the influence of synoptic forcing as well as the primary impacts of the Antarctic terrain. Cullather et al. [this issue] follow with a comprehensive evaluation of recent operational numerical analyses against available Antarctic observations and find that the European Centre for Medium-Range Weather Forecasts (ECMWF) assimilation analyses provide a reasonable depiction of the synoptic scale atmospheric circulation.

The next six contributions focus on boundary layer processes. Parish and Bromwich [this issue] use ECMWF analyses to demonstrate that the mass transport tied to the katabatic wind regime is responsible for the large pressure decreases over Antarctica in fall and rises in spring; the associated meridional mass circulation encompasses two thirds of the southern hemisphere and influences the behavior of midlatitude cyclones. Rogers et al. [this issue] describe a similar phenomenon over Greenland during spring where the impact of the North Atlantic atmospheric circulation is decisive. Stearns et al. [this issue] use automatic weather station observations to depict the gravitydriven divergent surface winds around the crest of the Greenland Ice Sheet; the impact of synoptic forcing decreases 
downslope of the highest parts of the terrain. Gallée and Duynkerke [this issue] perform simulations of the impact of katabatic winds on the summer ice-surface mass balance at the periphery of Greenland in the presence of weak synoptic forcing. Heinemann [this issue] presents three-dimensional simulations of katabatic winds in the Weddell Sea area of Antarctica and shows that shallow mesoscale cyclones form over the ice-free ocean during winter and summer (related papers are discussed in the next paragraph). Gallée [this issue] simulates the intense winter air-sea interactions associated with the katabatic wind-forced polynya in Terra Nova Bay, Antarctica, but does not consider the profound impacts of synoptic scale cyclones [Kurtz and Bromwich, 1985]. From research aircraft observations, Curry et al. [this issue] describe the evolution during the fall of the characteristics of boundary layer clouds formed by synoptic scale advection into the Beaufort Sea. Finally, Pinto and Curry [this issue] use a mesoscale model to demonstrate the importance of radiation to the formation of boundary layer stratus clouds and the evolution of an anticyclone over the Beaufort Sea during summer.

The next seven papers on mesoscale cyclones complement the recent special issues of the Global Atmosphere and Ocean System [Carleton, 1996a, b] on this topic. First, Carleton and Song [this issue] interpret 7 months of thermal infrared satellite images to ascertain the behavior of mesoscale cyclones in the Australasian sector of the Southern Ocean and outline some intriguing remote associations. McMurdie et al. [this issue] use multiple satellite sensors to establish quantitative descriptions of mesoscale cyclones over the Southern Ocean. Marshall and Turner [this issue] apply scatterometer winds from ERS 1 to describe the surface circulations of mesoscale cyclones around the Antarctic Peninsula. In two papers, Carrasco et al. [this issue $(\mathrm{a}, \mathrm{b})]$ establish the spatial and temporal variations of mesoscale cyclogenesis over Marie Byrd Land of West Antarctica and near the Antarctic Peninsula throughout 1991. Nielsen [this issue] applies output from a numerical forecast model to infer the mechanisms causing an atypical polar low formation over the Norwegian Sea during early fall. Finally, Rasmussen et al. [this issue] focus on the formation of a mesoscale cyclone and its associated sharp, low-level cold front over Fram Strait in spring.

The final four manuscripts are concerned with precipitation, which primarily is linked to synoptic scale cyclones. Liu and Curry [this issue] present the first satellite passive microwave algorithm for snowfall estimation over open ocean and apply it to characterize the winter precipitation over the Greenland-Iceland-Norwegian Seas during 1 month. Turner et al. [this issue] exploit synoptic weather observations from Faraday Station on the west side of the Antarctic Peninsula to show that the number of precipitation occurrences during winter has increased by about $50 \%$ since the 1950 s as a result of changes in synoptic activity. Hogan [this issue] synthesizes all available information to establish the dominant path of warm, moist air advection across West Antarctica which yields precipitation at the south pole. Hogan and Gow [this issue] examine a 200year record of annual snow accumulation (primarily from snowfall) amounts for south pole and find the frequency distribution of amounts to be lognormal; they propose the geometric standard deviation of annual accumulation amounts as a climatic index.
Acknowledgments. Preparation of this introduction as well as editorial duties for this special section was supported by National Aeronautics and Space Administration grants NAGW-2718 and NAGW-3677 and by National Science Foundation grant OPP9417983. John Turner provided important input for this introduction.

\section{References}

Carleton, A.M. (Ed.), Cold air mesocyclones in the Arctic and Antarctic, I, Global Atmos. Ocean Syst., 4, 1-361, $1996 \mathrm{a}$.

Carleton, A.M. (ed.), Cold air mesocyclones in the Arctic and Antarctic, II, Global Atmos. Ocean Syst., 5, 1-97, 1996b.

Carleton, A.M., and Y. Song, Synoptic climatology and intrahemispheric associations of cold air mesocyclones in the Australasian sector, J. Geophys. Res., this issue.

Carrasco, J.F., D.H. Bromwich, and Z. Liu, Mesoscale cyclone activity over Antarctica during 1991, 1, Marie Byrd Land, $J$. Geophys. Res., this issue (a).

Carrasco, J.F., D.H. Bromwich, and Z. Liu, Mesoscale cyclone activity over Antarctica during 1991, 2, Near the Antarctic Peninsula, J. Geophys. Res., this issue (b).

Cullather, R.I., D.H. Bromwich, and R.W. Grumbine, Validation of operational numerical analyses in Antarctic latitudes, J. Geophys. Res., this issue.

Curry, J.A., J.O. Pinto, T. Benner, and M. Tschudi, Evolution of the cloudy boundary layer during the autumnal freezing of the Beaufort Sea, J. Geophys. Res., this issue.

Gallée, H., Air-sea interactions over Terra Nova Bay during winter: Simulation with a coupled atmosphere-polynya model, $J$. Geophys. Res., this issue.

Gallée, H., and P.G. Duynkerke, Air-snow interactions and the surface energy and mass balance over the melting zone of West Greenland during the Greenland Ice Margin Experiment, $J$. Geophys. Res., this issue.

Heinemann, G., Idealized simulations of the Antarctic katabatic wind system with a three-dimensional mesoscale model, J. Geophys. Res., this issue.

Hines, K.M., D.H. Bromwich, and Z. Liu, Combined GCM and mesoscale model simulations of Antarctic climate, J. Geophys. Res., this issue.

Hogan, A.W., A synthesis of warm air advection to the South Polar Plateau, J. Geophys. Res., this issue.

Hogan, A.W., and A.J. Gow, Occurrence frequency of thickness of annual snow accumulation layers at the south pole, $J$. Geophys. Res., this issue.

Krinner, G., C. Genthon, Z.-X. Li, and P. Le Van, Studies of the Antarctic climate with a stretched-grid general circulation model, J. Geophys. Res., this issue.

Kurtz, D.D., and D.H. Bromwich, A recurring, atmospherically forced polynya in Terra Nova Bay, in Oceanology of the Antarctic Continental Shelf, Antarct. Res. Ser., vol. 43, edited by S.S. Jacobs, pp. 177-201, AGU, Washington, D. C., 1985.

Liu, G., and J.A. Curry, Precipitation characteristics in the Greenland-Iceland-Norwegian Seas determined using satellite microwave data, J. Geophys. Res., this issue.

Marshall, G.J., and J. Turner, Surface wind fields of Antarctic mesocyclones derived from ERS-1 scatterometer data, $J$. Geophys. Res., this issue.

McMurdie, L.A., C. Claud, and S. Atakturk, Satellite-derived atmospheric characteristics of spiral and comma-shaped southern hemisphere mesocyclones, J. Geophys. Res., this issue.

Moritz, R.E., and D.K. Perovich (Eds.), Surface heat budget of the Arctic Ocean Science Plan, ARCSS/OAII Rep. 5, 64 pp., Univ. of Wash., Seattle, 1996.

Nielsen, N.W., An early-autumn polar low formation over the Norwegian Sea, J. Geophys. Res., this issue.

Parish, T.R., and D.H. Bromwich, On the forcing of seasonal changes in surface pressure over Antarctica, J. Geophys. Res., this issue.

Pinto, J.O., and J.A. Curry, Role of radiative transfer in the modeled mesoscale development of summertime Arctic stratus, J. Geophys. Res., this issue.

Rasmussen, E.A., P.S. Guest, and K.L. Davidson, Synoptic and mesoscale atmospheric features over the ice-covered portions of Fram Strait in spring, J. Geophys. Res., this issue. 
Rogers, J.C., R.A. Hellstrom, E. Mosley-Thompson, and C.-C. Wang, An abrupt spring air temperature rise over the Greenland Ice Cap, J. Geophys. Res., this issue.

Stearns, C.R., G.A. Weidner, and L.M. Keller, Atmospheric circulation around the Greenland Crest, J. Geophys. Res., this issue.

Turner, J., et al., The Antarctic First Regional Observing Study of the Troposphere (FROST) project, Bull. Am. Meteorol. Soc., 77, 2007-2032, 1996.

Turner, J., S.R. Colwell, and S. Harangozo, Variability of precipitation over the coastal western Antarctic Peninsula from synoptic observations, J. Geophys. Res., this issue.
D. H. Bromwich, Polar Meteorology Group, Byrd Polar Research Center, The Ohio State University, 108 Scott Hall, 1090 Carmack Road, Columbus, $\mathrm{OH}$ 43210-1002. (e-mail: bromwich@polarmet1.mps.ohio-state.edu)

(Received March 28, 1997; revised April 21, 1997; accepted April 30, 1997.) 